\title{
Bicondylar tibial plateau fractures treated with fine-wire circular external fixation
}

\author{
N. Ferreira $\cdot$ L. C. Marais
}

Received: 4 June 2013/Accepted: 26 January 2014/ Published online: 9 February 2014

(C) The Author(s) 2014. This article is published with open access at Springerlink.com

\begin{abstract}
Bicondylar tibial plateau fractures are serious injuries to a major weight-bearing joint. These injuries are often associated with severe soft tissue injuries that complicate surgical management. We reviewed 54 consecutive patients who sustained bicondylar tibial plateau fractures that were treated with limited open reduction and cannulated screw fixation combined with fine-wire circular external fixation. Forty-six patients met the inclusion criteria of this retrospective review. Eight patients were excluded because they did not complete a minimum of 1-year follow-up. Thirty-six patients had Schatzker typeVI, and ten patients had Schatzker type-V fractures. All fractures were united without loss of reduction; there were no incidences of wound complications, osteomyelitis or septic arthritis. The average Knee Society Clinical Rating Score was 81.6, translating to good clinical results. Minor pin track infection was the most common complication encountered. This review concludes that fine-wire circular external fixation, combined with limited open reduction and cannulated screw fixation, consistently produces good functional results without serious complications.
\end{abstract}

Keywords Tibial plateau fracture - External fixator . Ilizarov

N. Ferreira $(\bowtie) \cdot$ L. C. Marais

Tumour, Sepsis and Reconstruction Unit,

Department of Orthopaedic Surgery, Greys Hospital,

University of KwaZulu-Natal,

Private Bag X9001, Pietermaritzburg 3201, South Africa

e-mail: drferreiran@gmail.com

\section{Introduction}

Bicondylar tibial plateau fractures are serious injuries that are often difficult to treat, even for the experienced trauma surgeon [1-4]. These fractures are frequently the result of high-energy trauma, and the condition of the soft tissues often mirrors the underlying bony injury [4-6]. These injuries are frequently associated with compartment syndrome or may present as open fractures [7].

Tibial plateau fractures are complex injuries that affect a major weight-bearing joint and are associated with significant morbidity $[3,8]$. Owing to the viscoelastic properties of bone, the tibia absorbs a large amount of energy at the time of injury. This energy is then expelled into the soft tissue envelope once bony failure occurs. The subcutaneous nature of the proximal tibia results in this energy being absorbed by a very thin soft tissue layer. This soft tissue envelope is intolerant of extensive dissection with implications for surgical management of the underlying bony injury $[2,3,5]$.

Open reduction and internal fixation, although convenient for the patient, have been associated with serious complications [5]. Several reports have shown a high incidence of wound complications with possibilities of deep sepsis and chronic osteomyelitis [5, 9-13].

Different strategies have been developed to overcome these complications with varying degrees of success. Monolateral external fixators have managed to decrease the soft tissue complications but not always maintained reduction until union [14, 15]. Circular external fixation has shown the ability to decrease soft tissue complications while providing stable fixation until union [16-19].

This retrospective study reports on the outcome from the management of high-energy tibial plateau fractures through limited open reduction and fine-wire circular external fixation. 
Table 1 Patient demographics

\begin{tabular}{|c|c|c|c|c|c|c|}
\hline & \multirow[t]{2}{*}{ Age/gender } & \multirow[t]{2}{*}{ Mechanism of injury } & \multirow[t]{2}{*}{ Schatzker } & \multicolumn{2}{|c|}{ Soft tissue injury } & \multirow[t]{2}{*}{ Additional injuries } \\
\hline & & & & Tscherne & Gustilo-Anderson & \\
\hline 1. & $38 \mathrm{M}$ & Pedestrian accident & VI & & IIIB & \\
\hline 2. & $43 \mathrm{~F}$ & Motor vehicle accident & VI & III & & \\
\hline 3. & $29 \mathrm{M}$ & Pedestrian accident & VI & III & & Contralateral tibial plateau fracture \\
\hline 4. & $34 \mathrm{M}$ & Motor vehicle accident & VI & & IIIA & \\
\hline 5. & $40 \mathrm{~F}$ & Fall & VI & III & & \\
\hline 6. & $57 \mathrm{M}$ & Pedestrian accident & VI & III & & \\
\hline 7. & $59 \mathrm{~F}$ & Pedestrian accident & VI & II & & Femur fracture \\
\hline 8. & $19 \mathrm{M}$ & Pedestrian accident & VI & & IIIB & Femur fracture \\
\hline 9. & $56 \mathrm{~F}$ & Motor vehicle accident & VI & III & & \\
\hline 10. & $42 \mathrm{M}$ & Fall & VI & III & & \\
\hline 11. & $37 \mathrm{M}$ & Fall & VI & III & & \\
\hline 12. & $21 \mathrm{~F}$ & Motor vehicle accident & $\mathrm{V}$ & III & & Contralateral tibia fracture \\
\hline 13. & $51 \mathrm{~F}$ & Motor vehicle accident & VI & III & & Acetabulum fracture, Monteggia fracture \\
\hline 14. & $50 \mathrm{M}$ & Motor vehicle accident & VI & III & & \\
\hline 15. & $40 \mathrm{M}$ & Assault & $\mathrm{V}$ & II & & \\
\hline 16. & $50 \mathrm{M}$ & Motor vehicle accident & $\mathrm{V}$ & II & & \\
\hline 17. & $52 \mathrm{M}$ & Pedestrian accident & VI & III & & \\
\hline 18. & $26 \mathrm{M}$ & Motor vehicle accident & VI & III & & Bilateral femur fracture \\
\hline 19. & $27 \mathrm{M}$ & Motor vehicle accident & $\mathrm{V}$ & II & & \\
\hline 20. & $59 \mathrm{M}$ & Motor vehicle accident & VI & III & & \\
\hline 21 & $41 \mathrm{~F}$ & Fall & $\mathrm{V}$ & III & & \\
\hline 22. & $46 \mathrm{M}$ & Fall & VI & III & & \\
\hline 23. & $34 \mathrm{M}$ & Fall & VI & III & & \\
\hline 24. & $43 \mathrm{~F}$ & Fall & VI & III & & Clavicle fracture \\
\hline 25. & $57 \mathrm{M}$ & Motor vehicle accident & VI & II & & Bilateral plateau fracture \\
\hline 26. & $57 \mathrm{M}$ & Motor vehicle accident & VI & II & & Bilateral plateau fracture \\
\hline 27. & $45 \mathrm{M}$ & Motor vehicle accident & VI & & IIIA & \\
\hline 28. & $36 \mathrm{M}$ & Fall & VI & III & & \\
\hline 29. & $53 \mathrm{M}$ & Bicycle accident & VI & III & & \\
\hline 30. & $43 \mathrm{M}$ & Pedestrian accident & VI & III & & \\
\hline 31. & $24 \mathrm{~F}$ & Fall & $\mathrm{V}$ & II & & \\
\hline 32. & $37 \mathrm{M}$ & Motor vehicle accident & $\mathrm{V}$ & I & & \\
\hline 33. & $28 \mathrm{~F}$ & Pedestrian accident & VI & II & & \\
\hline 34. & $33 \mathrm{M}$ & Fall & VI & III & & Intercondylar femur fracture \\
\hline 35. & $26 \mathrm{~F}$ & Fall & $\mathrm{V}$ & I & & \\
\hline 36. & $51 \mathrm{M}$ & Pedestrian accident & VI & III & & \\
\hline 37. & $52 \mathrm{~F}$ & Fall & VI & III & & \\
\hline 38. & $47 \mathrm{M}$ & Motor vehicle accident & VI & & IIIA & \\
\hline 39. & $41 \mathrm{M}$ & Fall & $\mathrm{V}$ & I & & \\
\hline 40. & $52 \mathrm{~F}$ & Fall & VI & III & & \\
\hline 41. & $52 \mathrm{M}$ & Pedestrian accident & VI & III & & \\
\hline 42. & $68 \mathrm{~F}$ & Motor vehicle accident & VI & III & & \\
\hline 43. & $37 \mathrm{~F}$ & Fall & $\mathrm{V}$ & III & & \\
\hline 44. & $56 \mathrm{~F}$ & Fall & VI & III & & \\
\hline 45. & $48 \mathrm{M}$ & Motor vehicle accident & VI & III & & Femur, tibia, tibial pilon fracture \\
\hline 46. & $41 \mathrm{~F}$ & Pedestrian accident & VI & II & & \\
\hline
\end{tabular}


Table 2 Management and complications

\begin{tabular}{|c|c|c|c|c|c|}
\hline & Co-morbidities & Fixator & Time to union (weeks) & Complications & Follow-up (months) \\
\hline 1. & None & Ilizarov & 34 & Meta-diaphyseal non-union & 18 \\
\hline 2. & None & Ilizarov & 14 & None & 24 \\
\hline 3. & None & Ilizarov & 18 & None & 24 \\
\hline 4. & None & Ilizarov & 20 & Compartment syndrome & 15 \\
\hline 5. & None & Ilizarov & 16 & Pin tract sepsis $\mathrm{C} \& \mathrm{O}$ II & 12 \\
\hline 6. & None & Ilizarov & 17 & Pin tract sepsis C\&O II & 12 \\
\hline 7. & None & Ilizarov & 28 & None & 12 \\
\hline 8. & None & Ilizarov & 22 & None & 21 \\
\hline 9. & None & Ilizarov & 26 & Pin tract sepsis C\&O II & 13 \\
\hline 10. & None & Ilizarov & 20 & Pin tract sepsis $\mathrm{C} \& \mathrm{O}$ II & 12 \\
\hline 11. & None & Ilizarov & 20 & None & 12 \\
\hline 12. & None & Ilizarov & 16 & None & 13 \\
\hline 13. & None & Ilizarov & 19 & None & 14 \\
\hline 14. & None & Ilizarov & 16 & None & 12 \\
\hline 15. & None & Truelok & 14 & Pin tract sepsis $\mathrm{C} \& \mathrm{O}$ II & 13 \\
\hline 16. & Smoker & Ilizarov & 12 & Pin tract sepsis C\&O IV & 12 \\
\hline 17. & None & Ilizarov & 18 & None & 17 \\
\hline 18. & HIV positive $\left(\mathrm{CD}_{4}=360\right)$ & Truelok & 54 & Meta-diaphyseal delayed union & 25 \\
\hline 19. & None & Ilizarov & 16 & None & 15 \\
\hline 20. & None & Ilizarov & 10 & None & 13 \\
\hline 21 & None & Truelok & 21 & None & 14 \\
\hline 22. & HIV positive $\left(\mathrm{CD}_{4}=352\right)$ & Ilizarov & 20 & None & 12 \\
\hline 23. & None & Ilizarov & 13 & Compartment syndrome & 24 \\
\hline 24. & None & Ilizarov & 19 & None & 15 \\
\hline 25 & Diabetes mellitus & Truelok & 13 & None & 24 \\
\hline 26. & Diabetes mellitus & Truelok & 13 & None & 24 \\
\hline 27. & Smoker & Ilizarov & 19 & Pin tract sepsis $\mathrm{C} \& \mathrm{O}$ III & 15 \\
\hline 28. & HIV positive $\left(\mathrm{CD}_{4}=309\right)$ & Ilizarov & 15 & None & 14 \\
\hline 29. & None & Truelok & 18 & Pin tract sepsis C\&O II & 18 \\
\hline 30. & None & Truelok & 17 & None & 12 \\
\hline 31. & None & Ilizarov & 19 & None & 12 \\
\hline 32. & None & Ilizarov & 18 & None & 13 \\
\hline 33. & RVD positive $\left(\mathrm{CD}_{4}=314\right)$ & Truelok & 15 & None & 14 \\
\hline 34. & None & Truelok & 16 & None & 13 \\
\hline 35. & None & Ilizarov & 9 & None & 12 \\
\hline 36. & HIV positive $\left(\mathrm{CD}_{4}=612\right)$ & Truelok & 10 & None & 17 \\
\hline 37. & Smoker & Truelok & 16 & Pin tract sepsis $\mathrm{C} \& \mathrm{O}$ II & 13 \\
\hline 38. & None & Truelok & 16 & None & 12 \\
\hline 39. & Smoker & Ilizarov & 19 & Pin tract sepsis $\mathrm{C} \& \mathrm{O}$ II & 12 \\
\hline 40. & Smoker & Ilizarov & 17 & Pin tract sepsis $\mathrm{C} \& \mathrm{O}$ II & 12 \\
\hline 41. & None & Truelok & 16 & None & 13 \\
\hline 42. & None & Truelok & 14 & None & 12 \\
\hline 43. & HIV positive $\left(\mathrm{CD}_{4}=407\right)$ & Truelok & 16 & None & 13 \\
\hline 44. & None & Truelok & 15 & None & 13 \\
\hline 45. & HIV positive $\left(\mathrm{CD}_{4}=347\right)$ & Ilizarov & 21 & None & 14 \\
\hline 46. & Smoker & Ilizarov & 30 & None & 12 \\
\hline
\end{tabular}




\section{Materials and methods}

Fifty-four patients (19 females and 35 males) with highenergy tibial plateau fractures were treated at our tertiary level government hospital between July 2008 and January 2012. All patients were treated with fine-wire circular external fixators for definitive management. The records of the skeletally mature patients with high-energy tibial plateau fractures were reviewed; no patients were lost to follow-up, but eight patients were excluded due to a follow-up period of $<1$ year. There were 46 patients ( 17 females and 29 males) who met the inclusion criteria (Table 1).

The mean age was 43 years (SD 11.1, range 19-68 years). Mechanisms of injury included pedestrianvehicle accidents $(n=12)$, occupants in motor vehicle accidents $(n=17)$, falls from height $(n=16)$, and assaults $(n=1)$. Ten patients also required treatment for associated musculoskeletal injuries (Table 1).

Host staging for comorbid issues included systemic factors such as HIV infection and $\mathrm{CD}_{4}$ count as well as any chronic medical conditions. HIV infection was found in seven patients ( $15 \%$ ) with $\mathrm{CD}_{4}$ counts ranging from 309 to 612 cells $/ \mathrm{mm}^{3}$ (median $=352$ cells $/ \mathrm{mm}^{3}$, SD 104.9). There were two diabetic patients, and six patients were smokers (Table 2). Local staging included classifying the soft tissue injuries according to the Gustilo-Anderson classification for open fractures and the Tscherne and Goetzen classification for closed fractures [20, 21]. There were plain X-rays and CT scans for all patients (Fig. 1). Fractures were classified according to the Schatzker classification [22]. Most of the patients sustained Schatzker type-VI fractures $(n=36)$ with the remainder being Schatzker type-V fractures $(n=10)$.

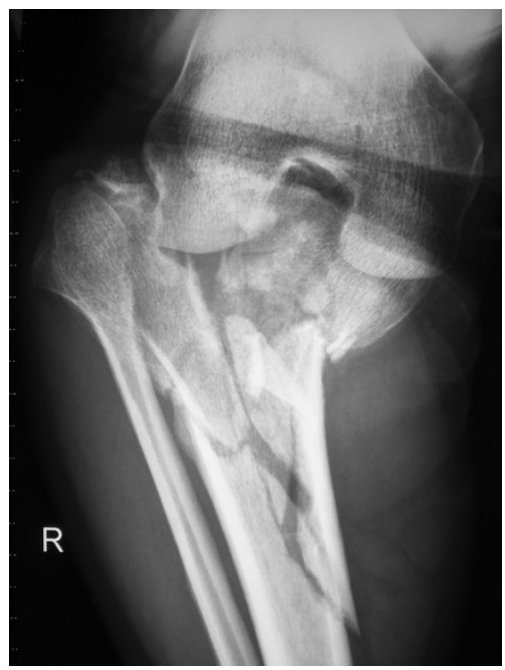

Fig. 1 52-year-old female with bicondylar tibial plateau fracture
Open fractures occurred in five patients (4 GustiloAnderson type IIIA and 1 Gustilo-Anderson type IIIB). These patients were taken to surgery on admission for debridement and temporary joint-spanning monolateral external fixation. Definitive wound cover was performed at $48 \mathrm{~h}$ for all open fractures. All Gustilo-Anderson type IIIA wounds were closed with delayed primary closure. A random fasciocutaneous flap was used to close the GustiloAnderson type IIIB wound. Compartment syndrome was diagnosed in two patients. Both patients were treated with emergency fasciotomies and temporary joint-spanning monolateral external fixators. Split skin grafts were used to close the fasciotomy wounds in both. The majority of the other patients had significant closed soft tissue injuries; these patients were initially treated with above-knee plaster of Paris backslabs and admitted to the ward for elevation.

The definitive surgical procedure was performed after the CT scan was available. The mean interval between admission and circular fixator application was 8.5 days (median $=7$ days, SD 5.5, range 1-21). The condition of the soft tissue envelope did not influence the timing of definitive surgery.

\section{Surgical technique}

A four-ring frame design was used in all cases. It consisted of three full rings and a $2 / 3$ rd proximal ring, open posteriorly, to allow knee flexion during rehabilitation. The $2 / 3$ rd ring was attached to a full ring via three $30-\mathrm{mm}$ spacers to prevent ring deformation during wire tensioning. The two distal rings were spread along the tibial diaphysis to provide optimal stability, while avoiding a span of $>150 \mathrm{~mm}$ between any rings (Fig. 2).

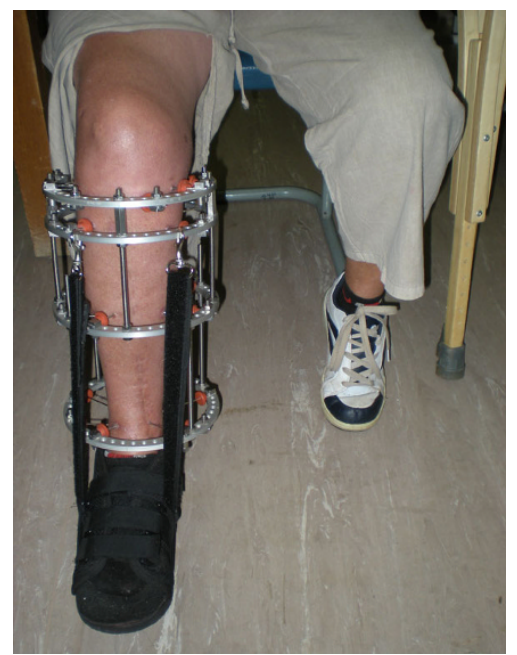

Fig. 2 Four ring frame designing with spread along entire length of tibia 




Fig. 3 Post-operative radiograph showing limited internal fixation and circular external fixator

The surgical technique included closed reduction or limited open reduction through a $2-\mathrm{cm}$ longitudinal midline incision. Fluoroscopy-guided reduction of the articular surface was performed via this incision and of any metadiaphyseal fracture lines. If fracture lines were not present or inadequate to allow insertion of instruments for reduction in articular fragments, a cortical window was created. After articular surface elevation, the resulting metaphyseal defect was grafted with iliac crest autograft. Due to the extensive articular comminution that was sometimes seen, anatomical joint reduction was not always possible.

After joint line alignment was achieved, a single $6.5-\mathrm{mm}$ cannulated screw was inserted from lateral to medial along the subchondral bone. This resulted in a single articular block and a diaphyseal fragment that could be aligned in the coronal and sagittal planes (Fig. 3). Four 1.8-mm olive wires were placed on the proximal ring, two transverse and two oblique. Two 1.8-mm wires were placed on each of the two distal rings. All wires were tensioned to between 110 and $130 \mathrm{~kg}$. Ilizarov (Smith and Nephew, Memphis, TN) fixators were used in 30 cases and TrueLok (Orthofix, Verona, Italy) fixators in 16 cases.

\section{Rehabilitation}

Post-operative rehabilitation commenced on day one after definitive fixation, and where possible, active-assisted knee range of motion exercises commenced. An attempt to achieve a $90^{\circ}$ arc of motion $\left(0^{\circ}-90^{\circ}\right)$ was made for all patients prior to discharge. Two patients had the initial circular fixators extended across the knee to allow healing of the soft tissues prior to knee mobilization. Once the soft tissues had healed sufficiently, the across-knee extension was removed and active-assisted knee range-of-motion exercises was commenced. All patients were encouraged to mobilize with full weight bearing as comfort allowed. In practice, most patients mobilized partial weight bearing with crutches and progressed to full weight bearing over the ensuing 2-3 weeks. Particular attention was paid to functional rehabilitation and normalization of gait pattern in order to promote recovery and bony union.

Pin site dressings were left undisturbed for the first 7-10 days following the definitive procedure. After this period, the dressings were removed, and twice daily pin site cleaning was commenced. Cleaning was performed in an atraumatic manner with the use of a swab soaked in an alcoholic solution of chlorhexidine. Pin site infections, when they occurred, were graded and treated according to the Checketts and Otterburn classification [23].

All patients were followed up at our orthopaedic outpatient department clinic. Initial 2-weekly follow-up visits were scheduled. The intervals were extended to 4-weekly once robust rehabilitation, and pin track care routines were established. Progress with rehabilitation, follow-up radiographs, and complications were documented with each clinic visit. The average follow-up time was 14.9 months (median $=13$ months, SD 4.1, range 12-25). The functional outcome was calculated with the Knee Society Clinical Rating Score [24]. The reported scores were obtained at a minimum follow-up of 6 months after frame removal.

\section{Results}

All fractures united in a mean of 18.3 weeks (median $=17$ weeks, SD 7.1, range 9-54; Table 2). Union was assessed clinically and radiologically. Once radiological union was deemed sufficient, the external fixator was dynamized and the patient encouraged to bear weight further. The external fixator was removed once painless weight bearing on a dynamized external fixator was achieved.

There was no loss of fracture reduction. Two patients had delayed union of the metaphyseo-diaphyseal fracture line. One of these patients underwent autologous bone grafting, and union was achieved at 24 weeks. The second patient declined bone grafting and eventually united at 54 weeks without any further surgical intervention.

The Knee Society Clinical Rating Scores ranged from 48 to 100 , translating into an average Knee Society Score of 81.6 (median $=83.8$, SD 12.9; Table 3). According to the rating, 22 outcomes were excellent, 16 were good, four were fair, and four were poor. The average arc of knee motion was $100.5^{\circ}$, ranging from $35^{\circ}$ to $125^{\circ}$. Seven patients developed varying degrees of knee flexion contractures. Three patients had a $5^{\circ}$ flexion contracture, while 
Table 3 Knee Society Clinical Rating Scale

\begin{tabular}{|c|c|c|c|c|}
\hline & Knee score & Functional score & Rating scale & Grade \\
\hline 1. & 85 & 90 & 87.5 & Excellent \\
\hline 2. & 65 & 55 & 60 & Fair \\
\hline 3. & 94 & 100 & 97 & Excellent \\
\hline 4. & 83 & 85 & 84 & Good \\
\hline 5. & 90 & 90 & 90 & Excellent \\
\hline 6. & 81 & 100 & 91 & Excellent \\
\hline 7. & 88 & 75 & 81.5 & Good \\
\hline 8. & 100 & 100 & 100 & Excellent \\
\hline 9. & 78 & 55 & 66.5 & Fair \\
\hline 10. & 90 & 90 & 90 & Excellent \\
\hline 11. & 80 & 45 & 62.5 & Fair \\
\hline 12. & 99 & 90 & 94.5 & Excellent \\
\hline 13. & 52 & 55 & 53.5 & Poor \\
\hline 14. & 73 & 75 & 74 & Good \\
\hline 15. & 80 & 85 & 82.5 & Good \\
\hline 16. & 78 & 70 & 74 & Good \\
\hline 17. & 88 & 70 & 79 & Good \\
\hline 18. & 78 & 70 & 74 & Good \\
\hline 19. & 95 & 100 & 97.5 & Excellent \\
\hline 20. & 77 & 80 & 78.5 & Good \\
\hline 21 & 69 & 45 & 57 & Poor \\
\hline 22. & 92 & 80 & 86 & Excellent \\
\hline 23. & 95 & 90 & 92.5 & Excellent \\
\hline 24. & 93 & 90 & 91.5 & Excellent \\
\hline 25. & 97 & 100 & 98.5 & Excellent \\
\hline 26. & 99 & 100 & 99.5 & Excellent \\
\hline 27. & 75 & 75 & 75 & Good \\
\hline 28. & 83 & 80 & 81.5 & Good \\
\hline 29. & 89 & 90 & 89.5 & Excellent \\
\hline 30. & 90 & 80 & 85 & Excellent \\
\hline 31. & 94 & 100 & 97 & Excellent \\
\hline 32. & 75 & 80 & 77.5 & Good \\
\hline 33. & 87 & 70 & 78.5 & Good \\
\hline 34. & 83 & 84 & 83.5 & Good \\
\hline 35. & 92 & 70 & 80.5 & Good \\
\hline 36. & 97 & 90 & 93.5 & Excellent \\
\hline 37. & 100 & 72 & 86 & Excellent \\
\hline 38. & 94 & 100 & 97 & Excellent \\
\hline 39. & 83 & 60 & 71.5 & Good \\
\hline 40. & 90 & 90 & 90 & Excellent \\
\hline 41. & 68 & 50 & 59 & Poor \\
\hline 42. & 99 & 75 & 87 & Excellent \\
\hline 43. & 90 & 80 & 85 & Excellent \\
\hline 44. & 80 & 80 & 80 & Good \\
\hline 45. & 67 & 30 & 48.5 & Poor \\
\hline 46. & 73 & 55 & 64 & Fair \\
\hline
\end{tabular}

another three had approximately $10^{\circ}$ of contracture. A severe flexion contracture of $20^{\circ}$ was seen in one patient. Thirty-two patients were able to ambulate without additional support, while 12 patients required a cane and two patients required crutches to aid mobilization.

Pin site infection was the most common complication occurring in 11 patients $(23.9 \%)$. Minor pin site infections occurred in ten of the 11 patients. These included nine Checketts and Otterburn grade II infections which were successfully treated with local pin track care and oral antibiotics. One patient developed a grade III infection which resolved after removal of the offending wire. A major infection occurred in one patient; this Checketts and Otterburn grade IV infection occurred at the end of the treatment period. The frame was removed without compromising the fracture treatment. No patients developed soft tissue complications. Wound dehiscence, infection, osteomyelitis of the fracture, or septic arthritis did not occur.

\section{Discussion}

The surgical treatment of bicondylar tibial plateau fractures is demanding, and the ideal treatment modality remains to be established [3]. In order to minimize joint stiffness and post-traumatic osteoarthritis, early joint mobilization is essential $[3,25,26]$. This is only possible if stable fixation is achieved to allow mobilization without loss of reduction.

In terms of mechanical stability, dual plating has traditionally been considered as the gold standard, as it addresses both the medial and lateral columns [22]. Extensive soft tissue dissection is required to place these plates, and high complication rates have been described, both with single and two incisional approaches [5, 9-13, 27]. Infection rates after open reduction and internal fixation reported by Jiang et al. [13], Yang et al. [27], and Moore et al. [9] are 7.3, 13.6, and $19 \%$ respectively, while Young et al. [10] reported an $87.5 \%$ infection rate after dual plating of high-energy bicondylar tibial plateau fractures. These post-operative infections impart significant additional morbidity. Barei et al. reported an average of 3.3 additional surgical procedures, and Young et al. an average of five additional surgical procedures to treat the infections $[5,10]$.

In order to minimize the soft tissue dissection in treating such fractures, monolateral external fixators were introduced to provide fracture stabilization. Although this strategy showed a decrease in the soft tissue complications $[14,15]$, mechanical stability was inadequate and loss of reduction was seen [15]. The reason for this mechanical 
failure is the cantilever loading forces that the external fixator is subjected to. This places the external fixator at a mechanical disadvantage when having to provide stability at a distance from the fixator body [28].

Circular external fixators utilize beam loading of the tensioned fine wires to provide stability across the entire length of the wire [28]. The surgeon can exploit this property with the use of multiple wires, to provide uniform support for the tibial plateau articular surface that may be likened to a custom raft-construct tailored to each individual fracture pattern. Biomechanical analysis demonstrated that four tensioned olive wires combined with a single lag screw provides better stability than dual plating [29]. For this reason, we always combine a single lag screw with four tensioned olive wires to the proximal ring. This method of fixation provides adequate stability to allow early joint mobilization and weight bearing without risking loss of reduction. None of our patients experienced postoperative loss of reduction when comparing immediate post-operative and latest follow-up radiographs.

An additional advantage with fine-wire circular fixators is the minimally invasive nature of its application [30]. In an area where the soft tissues are often compromised, additional surgical trauma could have undesirable consequences $[28,30]$. Fine wires passed through compromised tissues impart almost no additional trauma and do not appear to cause any morbidity. None of our patients had soft tissue complications from either the wire insertion sites or other minimal invasive incision sites. Multiple previous investigations have shown benefit from this surgical technique. Kataria et al. [16] reported on a series of 38 patients and had no incidences of non-union or septic arthritis. Dendrinos et al. [19], Ali et al. [17], and Chin et al. [18] treated 24, 20, and 18 patients respectively, all with no infective complications. Our results add to this body of literature, with no cases of wound dehiscence, infection, osteomyelitis, or septic arthritis encountered.

The benefit of early definitive surgical stabilization is early mobilization. This is advantageous as it decreases delays in functional rehabilitation that may negatively impact outcome. The average functional outcome, measured with the Knee Society Clinical Rating Score achieved in our series, was 81.0. This compares favourably to other published studies with average Knee Rating scores ranging from 65.9 to 80.2 [18, 31-33]. These initial functional results appear to be maintained over the medium-tolong term, as illustrated by Katsenis et al. [34] over a minimum 5-year follow-up.

Pin track sepsis remains a common complication with the use of external fixators [35, 36]. Quoted incidences range from 11.3 to $100 \%$ [37-41]. Fortunately, the majority of these infections are minor and easily treated with local pin track care and oral antibiotics [42]. Intra-operative pin insertion methods that emphasize low energy insertion and a standardized post-operative pin track care protocol have been shown to be effective in reducing the incidence and severity of pin tract sepsis [43]. These strategies should be instituted for all patients who undergo external fixator application. In our series, only one patient developed a major pin track infection that required removal of the external fixator. Ten patients had minor pin track sepsis that responded to local treatment and oral antibiotics. It is interesting to note that HIV infection had no influence on the incidence or severity of pin track sepsis, while five out of six patients who smoked developed pin track sepsis.

\section{Conclusion}

Fine-wire circular external fixation with limited open reduction is an effective treatment for high-energy tibial plateau fractures. This treatment strategy has the ability to produce good functional results for the majority of patients while minimizing serious complications.

Conflict of interest The authors declare that they have no conflict of interest.

Open Access This article is distributed under the terms of the Creative Commons Attribution License which permits any use, distribution, and reproduction in any medium, provided the original author(s) and the source are credited.

\section{References}

1. Furey A, Floyd JCP, O'Toole RV (2007) Treatment of tibial plateau fractures. Curr Opin Orthop 18:49-53

2. Narayan B, Harris C, Nayagam S (2006) Treatment of highenergy tibial plateau fractures. Strateg Trauma Limb Reconstr $1: 18-28$

3. Papagelopoulos PJ, Partsinevelos AA, Themistocleous GS, Mavrogenis AF, Korres DS, Soucacos PN (2006) Complications after tibial plateau fracture surgery. Injury 37:475-484

4. Kulkarni GS, Kulkarni MG, Kulkarni SG, Kulkarni RM, Kulkarni VS, Shah AN (2001) Surgical treatment of tibial plateau fractures. Orthop Traumatol 9:263-272. doi:10.1007/s00065-0011028-2

5. Barei DP, Nork SE, Mills WJ, Bradford Henley M, Benirschke SK (2004) Complications associated with internal fixation of high-energy bicondylar tibial plateau fractures utilizing a twoincision technique. J Orthop Trauma 18:649-657

6. Weigel DP, Marsh JL (2002) High-energy fractures if the tibial plateau. J Bone Jt Surg 84-A:1541-1551

7. Ferreira N, Senoge ME (2011) Functional outcome of bicondylar tibial plateau fractures treated with the Ilizarov circular external fixator. SA Orthop J 10(3):80-84

8. Gaston P, Will EM, Keating JF (2005) Recovery of knee function following fracture of the tibial plateau. J Bone Jt Surg (Br) 87-B:1233-1236

9. Moore TM, Patzakis MJ, Harvey JP (1987) Tibial plateau fractures, definition, demographics, treatment rationale and long term 
results of closed traction management or operative reduction. J Orthop Trauma 1(2):97-119

10. Young MJ, Barrack RL (1994) Complications of internal fixation of tibial plateau fractures. Orthop Rev 23:149-154

11. The Canadian Orthopaedic Trauma Society (2006) Open reduction and internal fixation compared with circular fixator application for bicondylar tibial plateau fractures. Results of a multicenter, prospective, randomized clinical trial. J Bone Joint Surg 88:2613-2623

12. Lee JA, Papadakis SA, Moon C, Zalavras CG (2007) Tibial plateau fractures treated with the less invasive stabilisation system. Int Orthop (SICOT) 31:415-418

13. Jiang R, Luo C, Wang M, Yang T, Zeng B (2008) A comparative study of less invasive stabilization system (LISS) fixation and two-incision double plating for the treatment of bicondylar tibial plateau fractures. Knee 8:139-143

14. Ries MD, Meinhard BP (1990) Medial external fixation with lateral plate internal fixation in metaphyseal tibia fractures. A Report of eight cases associated with severe soft tissue injury. Clin Orthop 256:215-223

15. Marsh JL, Smith ST, Do TT (1995) External fixation and limited internal fixation for complex fractures of the tibial plateau. J Bone Jt Surg Am 77:661-673

16. Kataria H, Sharma N, Kanojia RK (2007) Small wire external fixation for high-energy tibial plateau fractures. J Orthop Surg 15(2):137-143

17. Ali AM, Burton M, Hashmi M, Saleh M (2003) Outcome of complex fractures of the tibial plateau treated with beam-loading ring fixation system. J Bone Jt Surg (Br) 85-B:691-699

18. Chin TYP, Bardana D, Bailey M, Williamson OD, Miller R, Edwards ER, Esser MP (2005) Functional outcome of tibial plateau fractures treated with the fine-wire fixator. Inj Int J Care Inj 36:1467-1475

19. Dendrinos GK, Kontos S, Katsenis D, Dalas A (1996) Treatment of high-energy tibial plateau fractures by the Ilizarov circular fixator. J Bone Jt Surg (Br) 78-B:710-717

20. Gustilo R, Mendoza R, Williams D (1984) Problems in the management of type III (severe) open fractures: a new classification of type III open fractures. J Trauma 24:742-746

21. Tscherne H, Gotzen L (1984) Fractures with soft tissue injuries. Springer, Berlin

22. Schatzker J, McBroom R, Bruce D (1979) The tibial plateau fracture. The Toronto experience 1968-1975. Clin Orthop Relat Res 138:94-104

23. Checketts RG, MacEachern AG, Otterburn M (2000) Pin track infection and the principles of pin site care. In: De Bastiani A, Graham Apley A, Goldberg A (eds) Orthofix external fixation in trauma and orthopaedics. Springer, Berlin, pp 97-103

24. Insall JN, Dorr LD, Scott RD, Normal Scott W (1989) Rationale of the Knee Society clinical rating system. Clin Orthop 248: 13-14

25. Apley AG (1956) Fractures of the lateral tibial condyle treated by skeletal traction and early mobilization: a review of sixty cases with special reference to the long-term results. J Bone Jt Surg (Br) 38-B:699-708

26. Apley AG (1979) Fractures of the tibial plateau. Orthop Clin N Am 10:61-74
27. Yang EC, Weiner L, Strauss E et al (1995) Metaphyseal dissociation fractures of the proximal tibia. An analysis of treatment and complications. Am J Orthop 244:695-704

28. Fragomen AT, Rozbruch SR (2007) The mechanics of external fixation. HSSJ 3:13-29

29. Watson JT, Ripple S, Hoshaw SJ, Fyhrie D (2002) Hybrid external fixation for tibial plateau fractures: clinical and biomechanical correlation. Orthop Clin N Am 33:199-209

30. Bronson DG, Samchukov ML, Birch JG, Browne RH, Ashman RB (1998) Stability of external circular fixation: a multi-variable biomechanical analysis. Clin Biomech 13:441-448

31. Mikulak SA, Gold SM, Zinar DM (1998) Small wire external fixation of high-energy tibial plateau fractures. Clin Orthop Relat Res 365:230-238

32. Kumar A, Whittle AP (2000) Treatment of complex (Schatzker type VI) fractures of the tibial plateau with circular wire external fixation: retrospective case review. J Orthop Trauma 14(5): 339-344

33. Subasi M, Kapukaya A, Arslan H, Ozkul E, Cebesoy O (2007) Outcome of open comminuted tibial plateau fractures treated using an external fixator. J Orthop Sci 12:347-353

34. Katsenis D, Dendrinos G, Kouris A, Savas N, Schoinochoritis N, Pogiatzis K (2009) Combination of fine wire fixation and limited internal fixation for high-energy tibial plateau fractures: functional results at minimum 5-year follow-up. J Orthop Trauma 23:493-501

35. Bibbo C, Brueggeman J (2010) Prevention and management of complications arising from external fixation pin sites. J Foot Ankle Surg 49:87-92

36. Rogers LC, Bevilacqua NJ, Frykberg RG, Armstrong DG (2007) Predictors of postoperative complications of Ilizarov external ring fixators in the foot and ankle. J Foot Ankle Surg 46(5):372-375

37. Cavusoglu AT, Er MS, Inal S, Ozsoy MH, Dincel VE, Sakaogullari A (2009) Pin site care during circular external fixation using two different protocols. J Orthop Trauma 23:724-730

38. DeJong ES, DeBerardino TM, Brooks DE, Nelson BJ, Campbell AA, Bottoni CR, Pusateri AE, Walton RS, Guymon CH, McManus AT (2001) Antimicrobial efficacy of external fixator pins coated with a lipid stabilized hydroxyapatite/chlorhexidine complex to prevent pin tract infection in a goat model. J Trauma 50:1008-1014

39. Mostafavi HR, Tornetta P III (1997) Open fractures of the humerus treated with external fixation. Clin Orthop Relat Res 337:187-197

40. Parameswaran AD, Roberts CS, Seligson D, Voor M (2003) Pin tract infection with contemporary external fixation: How much of a problem? J Orthop Trauma 17:503-507

41. Patterson MM (2005) Multicentre pin care study. Orthop Nurs 24(5):349-360

42. Ferreira N, Marais LC (2012) Pin tract sepsis: incidence with the use of circular fixators in a limb reconstruction unit. SA Orthop J 11(1):10-18

43. Ferreira N, Marais LC (2012) Prevention and management of external fixator pin tract sepsis. Strateg Trauma Limb Reconstr 7:67-72. doi:10.1007/s11751-012-0139-2 